\title{
Community treatment orders in New Zealand
}

\author{
John Dawson
}

Professor, Faculty of Law, University of Otago, Dunedin, New Zealand, email john.dawson@otago.ac.nz

\begin{abstract}
$\mathrm{M}$ any legal mechanisms can be used to authorise compulsory community mental healthcare: leave or conditional discharge for compulsory in-patients; adult guardianship (or incapacity) legislation; treatment as a condition of a community-based criminal sentence, like probation, or of parole from imprisonment; or a fullfledged community treatment order (CTO) scheme. It is the specific mix of mechanisms employed in a particular jurisdiction that will characterise how that legal system manages the delivery of compulsory (or quasi-consensual) community psychiatric care.

In New Zealand, the preferred mechanism since 1992 has been a clearly structured CTO regime. This regime is widely used, endorsed by most New Zealand clinicians (Romans et al, 2004) and the most common mechanism for delivering any form of involuntary psychiatric care. In 2007, 61 persons per 100000 were on a CTO in New Zealand. This is 4 times the number under compulsory in-patient care and 12 times the number on in-patient leave (Office of the Director of Mental Heath, 2008).
\end{abstract}

\section{The New Zealand context}

This extensive use of CTOs in New Zealand occurs within a particular service environment, involving the thoroughgoing deinstitutionalisation of mental healthcare and the build-up of mobile community mental health teams (Dawson, 2005). It also proceeds against the backdrop of New Zealand's relatively strong social welfare traditions.

The CTOs are implemented mainly through a network of experienced community mental health nurses, who visit patients wherever they live and supervise their medication. These nurses, and other members of community mental health teams, work as the salaried employees of regionally organised public health services that provide both in-patient and out-patient care. In addition, in many places supported accommodation run by not-for-profit organisations is available for CTO patients, along with long-term social welfare payments to support their community tenure.

No unreasonable form of liability is imposed by law on clinicians who operate the CTO regime. There is no entrenched bill of rights within New Zealand's constitutional arrangements that constrains the design of the mental health legislation, and a less libertarian political culture obtains - that puts less emphasis on the right of individuals with a mental illness to be left alone, and more emphasis on maintaining their connections with their family - than might be found in some other parts of the world.

In this milieu, the New Zealand CTO regime has been aimed at those with a serious and continuing mental illness who are considered by clinicians to need ongoing medication and supervision. The regime is used in a preventive manner, mainly for patients who fit the common profile of those placed under CTOs wherever such regimes are found. This profile is described by Churchill et al (2007, p. 109) in their review of the research: the majority of CTO patients are male, with an average age of about 40 years, 'with a long history of mental illness, previous admissions, suffering from a schizophrenia-like or serious affective illness, and likely to be displaying psychotic symptoms, especially delusions, at the time'.

In practice, imminent danger to self or others is not required in New Zealand for the CTO to be maintained. It is usually considered sufficient that the patient would, without treatment, have a seriously diminished capacity for self-care. Clear enforcement mechanisms are then provided, but substantial elements of due process and professional accountability also apply. A CTO is made in New Zealand by a lower court judge, usually about a month after a patient's compulsory admission to hospital, when a private judicial hearing is held, at which the patient may be represented by a lawyer and at which the family may appear.

Once made, the CTO lasts initially for 6 months and may be renewed, but mandatory clinical reviews must be conducted. The patient may be discharged from the order at any time by the responsible clinician, and may appeal periodically for release to a multidisciplinary review tribunal. Lawyers, called district inspectors, are appointed to advise compulsory patients of their review entitlements. The use without the patient's consent of either long-term medication or electroconvulsive therapy is subject to mandatory peer review by a second, senior psychiatrist appointed by the review tribunal.

\section{The precise legal criteria}

Under New Zealand's Mental Health (Compulsory Assessment and Treatment) Act 1992, four distinct legal criteria must be met for a CTO to be made (sections 2, 27, 28):

$O$ the patient must have an 'abnormal state of mind' of the necessary kind

O this must be 'of such a degree that it poses' a serious danger to the health or safety of that person or others, or seriously diminishes the person's capacity for self-care

O involuntary treatment must be 'necessary'

$O$ adequate out-patient care and community support must be 'available'.

The New Zealand legislation specifically lists the necessary characteristics of this 'abnormal state of mind'. It may be 'continuous or intermittent', but must be 'characterised by 
delusions, or by a disorder of mood or perception or volition or cognition' (section 2). Those with personality disorders may be treated under the Act, therefore, only if they present one of those listed disorders of mental function. Furthermore, no person may be placed under compulsory treatment 'by reason only of intellectual disability' (section 4(e)). In effect, New Zealand has adopted into legislation the position taken by Aubrey Lewis, that mental illness is best defined in terms of 'evident disturbance of part-functions' of the mind, not in terms of disturbed social functioning alone (Lewis, 1953, p. 118). The overwhelming majority of patients under CTOs in New Zealand have a diagnosis of schizophrenia, schizoaffective psychosis or major affective disorder (Dawson \& Romans, 2001).

\section{Conditions of a СTO}

Patients under a CTO will usually be required to accept visits (often weekly) at their residence from a community nurse, attend out-patient appointments with a psychiatrist (often monthly) and take medication as prescribed. They may also be required to live in a specified kind of accommodation, with certain levels of support, and to avoid substance misuse. The main legal mechanism for enforcing these conditions is the threat of return to in-patient care, as the responsible clinician may revoke the CTO whenever the patient 'cannot continue to be treated adequately as an outpatient' (section 29). Police assistance is available with that recall process, if required.

There is no express power, however, to use 'forced medication' in a community setting. That practice is widely considered unsafe and unethical, and is explicitly rejected in the New Zealand Ministry of Heath's guidelines to the Act (Dawson, 2006). If patients adamantly refuse treatment, they must be returned to hospital for it to proceed, where proper assessment and observation can occur.

Whether a patient will be returned to hospital in practice for breaching the conditions of a CTO remains a matter of discretion, however, for the clinical team. The critical factors seem to be the relapse profile of the patient, the likely consequences of a relapse and the impact of recall on the therapeutic alliance (Mullen et al, 2006a). Also, a bed must be available. In practice, recall is not common: we found patients averaged 2.3 years of involuntary out-patient care per recall to hospital. Nevertheless, a small minority of patients were repeatedly recalled (Mullen et al, 2006a).

\section{The attitudes of participants to this regime}

A national survey of psychiatrists conducted 10 years into the operation of this regime (Romans et al, 2004) found the great majority endorsed it, seeing it as a useful tool in pursuit of core clinical aims for people with a serious mental illness. CTOs were considered to work in a largely structural and indirect fashion, providing the authority to maintain contact with out-patients, binding into place the necessary services, and promoting medication compliance and early identification of relapse. CTOs were considered to support the involvement of families and other agencies in patients' care, and to have a significant impact on patients' attitudes to their illness, by communicating the seriousness with which others viewed their condition. Compulsion was not seen as a substitute for adequate service provision. On the contrary, success was seen to depend on the quality and extent of services available, especially the skills of community nurses and an adequate range of supported accommodation.

A small minority of New Zealand psychiatrists, though, did not endorse the regime, mainly because they had concerns about the long-term impact on the therapeutic alliance. The predominant view, however, was that, while compulsion can harm relations in the short term, the advantages of sustained community treatment usually outweigh this problem, and that, when greater insight follows treatment, therapeutic relations often improve in the end.

Family members interviewed also showed high levels of support for the regime (Mullen et al, 2006b) and even many patients under CTOs were found, to our surprise, either to be ambivalent about their own compulsory community care or to be mildly supportive of their treatment under the regime, often because of their strong desire to avoid further institutional care (Gibbs et al, 2005).

In these circumstances, there is currently no major political momentum in New Zealand for repeal or significant reform of the CTO regime. It is widely viewed as an adequate means of delivering compulsory care to those with a serious and persistent mental illness, in a radically deinstitutionalised environment, within the welfare state.

\section{References}

Churchill, R., Owen, G., Singh, S., et al (2007) International Experience of Using Community Treatment Orders. Institute of Psychiatry.

Dawson, J. (2005) Community Treatment Orders: International Comparisons. Otago University Print (http://www.otago.ac.nz/law/otagoCTO/ index.html).

Dawson, J. (2006) Fault-lines in community treatment order legislation. International Journal of Law and Psychiatry, 29, 482-494.

Dawson, J. \& Romans, S. (2001) Use of community treatment orders in New Zealand: early findings. Australian and New Zealand Journal of Psychiatry, 35, 190-195.

Gibbs, A., Dawson, J., Ansley, C., et al (2005) How patients in New Zealand view community treatment orders. Journal of Mental Health, 14, 357-368.

Lewis, A. (1953) Health as a social concept. British Journal of Sociology, 4, 109-124.

Mullen, R., Dawson, J. \& Gibbs, A. (2006a) Dilemmas for clinicians in use of community treatment orders. International Journal of Law and Psychiatry, 29, 535-550.

Mullen, R., Gibbs, A. \& Dawson, J. (2006b) Family perspective on community treatment orders: a New Zealand study. International Journal of Social Psychiatry, 52, 469-478.

Office of the Director of Mental Heath (2008) Annual Report 2007. Ministry of Health.

Romans, S., Dawson, J., Mullen, R., et al (2004) How mental health clinicians view community treatment orders: a national New Zealand survey. Australian and New Zealand Journal of Psychiatry, 38, 836841 